\title{
Typing and Grading of Soft Tissue Tumors and their Correlation with Proliferative Marker Ki-67
}

Sumiti Gupta ${ }^{1}$, Samta Shakya ${ }^{1}$, Meenu Gill ${ }^{1}$, Sonia Hasija ${ }^{2 *}$, Nisha Marwah ${ }^{1}$, Rajnish Kalra ${ }^{1}$ and Rajeev Sen ${ }^{1}$

${ }^{1}$ Department of Pathology, PGIMS, Rohtak Haryana, India

${ }^{2}$ Department of Pathology, SHKM, GMC, Nalhar, Mewat Haryana, India

\begin{abstract}
Aim and Objective: The main aim of this study is to categorize, type, grade of soft tissue tumors \& correlate it with Ki-67 proliferative index.

Material and Methods: The present study was conducted in the Department of Pathology, PGIMS, Rohtak The study group comprised of excised 44 cases of STT (soft tissue tumors) specimens. Tumor grade was assigned based on the FNCLCC (Fédération Nationale des Centers de Lutte Contre le Cancer) grading system. According to the Ki-67 index the patients were divided into two groups: high index group (>50/10HPF) and low index group $(<50 / 10 \mathrm{HPF})$. These grades were correlated with proliferative activity using Ki-67 index.

Results: Out of 44 soft tissue tumors in our study $12(27.27 \%)$ were diagnosed as benign and $32(72.72 \%)$ were diagnosed as malignant soft tissue tumors. Average size of benign tumors was $4.50 \mathrm{~cm}$ and that of malignant tumors was $10.33 \mathrm{~cm}$. Maximum number of soft tissue tumor were located in the extremities i.e. $10(22.72 \%)$ in upper extremity and $24(54.54 \%)$ in the lower extremity. The commonest site affected was thigh $(18.2 \%)$. Out of the 32 cases of (STS) soft tissue sarcomas, $15(46.87 \%)$ were Grade 2, $13(40.63 \%)$ were Grade 3 and $4(12.5 \%)$ were Grade 1. MPNST (malignant peripheral nerve sheath tumor) had the largest number of cases with Grade $3(31.3 \%)$. All the benign STT had low Ki-67 index, while the Ki-67 index was low in 12 STS and high in 20 STS. The size as well as grade of the tumors showed a significant correlation with Ki-67 index.

Conclusion: Grading based on assessment of morphologic variables is one of the most important factors for predicting the prognosis of the patients with STS. Therefore, it should be a part of the pathology report and should be adapted to the modern management of patients.
\end{abstract}

Keywords: Soft tissue tumors (STT); Soft tissue sarcomas (STS); Ki-67

\section{Introduction}

Soft tissue can be defined as non-epithelial extraskeletal tissue of the body exclusive of the reticuloendothelial system, glia, and supporting tissue of various parenchymal organs. Embryologically, soft tissue is derived principally from mesoderm, with some contribution from neuroectoderm [1]. Soft tissue tumors (STT) are a highly heterogeneous group of tumors that are classified on a histogenetic basis according to the adult tissue they resemble. Within the various histogenetic categories, soft tissue tumors are usually divided into benign and malignant forms [1]. Benign mesenchymal tumors outnumber sarcomas by a factor of at least 100. Like almost all other malignancies, soft tissue sarcomas become more common with increasing age, the median age being 65 years. There is a slight male predominance [2]. Sarcomas form $7-15 \%$ of pediatric malignancies in first year of life. Incidence of STT is difficult to assess because not all benign STT get biopsied [3]. Soft tissue sarcomas may occur anywhere but three fourths are located in the extremities (most common in thigh) and 10 percent each in the trunk wall and retroperitoneum. Proliferation is accessed by counting the number of mitotic figures per tumor area, determining the S-phase fraction (SPF) by flow cytometry, labeling of proliferating cells with radioactive thymidine, and IHC staining for growth-phase specific proteins such as Ki-67. The S-phase fraction (SPF) has been shown to discriminate prognostic high-risk and lowrisk patients for metastasis in STS but the technique is hampered by $30-40 \%$ non-informative histograms. Labeling of proliferating cells with radioactive thymidine is a laboratory-intense technique that is currently not commonly used, whereas IHC staining of $\mathrm{Ki}-67$ protein is easy to perform and thus suitable for routine use [4]. So, in the present study we correlate the morphologic parameters of soft tissue tumors with expression of Ki-67, proliferation marker.

\section{Materials and Methods}

The present study was conducted in the Department of Pathology Pt. B.D. Sharma, PGIMS, Rohtak. The study group comprised of forty four cases of soft tissue tumor specimens. The study included only excision biopsies and resected specimens of tumors. Incisional biopsies were excluded. The tissue was fixed in buffered formalin ( $\mathrm{pH} 7.0$ ), and embedded in paraffin. The tissue block was sectioned at, 4-5 $\mu \mathrm{m}$ and the sections were stained for haematoxylin and eosin and examined. Sections from representative tumor block were subjected to routine IHC panel and special stains required for subtyping of tumor [5]. One section each of the representative block was subjected to proliferation marker Ki-67. Tumor grade was assigned based on the FNCLCC (Fédération Nationale des Centres de Lutte Contre le Cancer) grading system which is based on 3 parameters (1) Tumor differentiation (2) Mitotic count (3) Tumor necrosis [1].

*Corresponding author: Sonia Hasija, H.No. 768, Sector- 47, Gurgaon, India, Tel: 09728141421; E-mail: drsoniahasija@gmail.com

Received February 17, 2015; Accepted March 30, 2015; Published April 01, 2015.

Citation: Gupta S, Shakya S, Gill M, Hasija S, Marwah N, et al. (2015) Typing and Grading of Soft Tissue Tumors and their Correlation with Proliferative Marker Ki-67. J Cytol Histol 6: 320. doi:10.4172/2157-7099.1000320

Copyright: @ 2015 Gupta S, et al. This is an open-access article distributed under the terms of the Creative Commons Attribution License, which permits unrestricted use, distribution, and reproduction in any medium, provided the original author and source are credited. 


\section{FNCLCC (Fédération Nationale des Centres de Lutte Contre le Cancer) Grading System: Definition of parameters [1]}

\section{Tumor differentiation:}

Score 1: Sarcomas closely resembling normal adult mesenchymal tissue (eg, well-differentiated liposarcoma)

Score 2: Sarcomas for which histologic typing is certain (e.g., myxoid liposarcoma)

Score 3: Embryonal and undifferentiated sarcomas; sarcomas of uncertain type

\section{Mitotic count:}

Score 1: 0-9 mitoses per $10 \mathrm{HPF}$

Score 2: 10-19 mitoses per $10 \mathrm{HPF}$

Score 3: $\geq 20$ mitoses per $10 \mathrm{HPF}$

\section{Tumor necrosis:}

Score 0: No necrosis

Score $1: \leq 50 \%$ tumor necrosis

Score 2: $>50 \%$ tumor necrosis

\section{Histologic grade:}

Grade 1: Total score 2, 3

Grade 2: Total score 4, 5

Grade 3: Total score 6, 7, 8

The Ki-67 immunoquantitation was performed using light microscopy at 400x magnification. Ki-67-positive tumor cells were clearly detected by their characteristic diffuse granular or globular nuclear staining (brown). All immunostained nuclei, independent of intensity, were scored as positive. The areas containing the largest number of Ki-67-positive cells were selected and the numbers of positive cells counted in $10 \mathrm{HPF}$ chosen at random. Then the scores were averaged to give Ki-67 index (the number of Ki-67-positive tumor cells/10HPF) in each case. According to the Ki-67 index the patients were divided into two groups: high index group $(>50 / 10 \mathrm{HPF})$, and low index group $(<50 / 10 \mathrm{HPF})$.

Stained sections were examined and each STS was graded according to FNCLCC Grading System. These grades were correlated with proliferative activity using Ki-67 index.

The results obtained were interpreted and descriptive statistics (mean, standard deviation, range, percentages) were applied wherever appropriate. Where the data was qualitative, a chi square test was used to assess the association between these parameters. A value of ' $p$ ' $<0.05$ was taken as significant and $<0.01$ as highly significant whereas the 'p'>0.05 was taken as non-significant. Spearman coefficient of correlation was calculated.

\section{Results}

The patients selected were tabulated for the study in the age group of $0-100$ years with the class interval of 10 years. It was observed that maximum cases $(29.5 \%)$ were in the age group of 31-40 years, followed by 7 (15.9\%) in 21-30 years age group. The youngest patient was 4 years of age and oldest one was of 81 years of age.

Out of 44 cases, $12(27.27 \%)$ cases were of benign soft tissue tumors and $32(72.73 \%)$ cases were of malignant soft tissue tumors. Out of total 12 benign cases, 8 were males (66.7\%) and 4 were females (33.3\%) with a sex ratio of 2:1. The mean age of the males with benign STT was 38.9 years while that of the females was 35.4 years. Out of total 32 malignant cases, 23 were males $(72 \%)$ and 9 were females $(28 \%)$ with a sex ratio of 2.5:1. The mean age of the males with malignant STT was 45.7 years while that of females was 38.1 years. It was observed that maximum number of STT were located in the extremities i.e.10 (22.72\%) in upper extremity and $24(54.54 \%)$ in the lower extremity. The commonest site affected was thigh (18.2\%). The size of the STT ranged from 1-29 $\mathrm{cm}$. Maximum number of STT $(\mathrm{n}=18)$ were of the size range $6-10 \mathrm{~cm}$, followed by 13 STT in the range of 11-15 cm. Only 1 tumor was more than $20 \mathrm{~cm}$. Out of the tumors in the size range $6-10 \mathrm{~cm}, 2(11.11 \%)$ were benign and $16(88.89 \%)$ were malignant. Average size of benign STT was $4.50 \mathrm{~cm}$ and that of malignant STT was $10.33 \mathrm{~cm}$.

Among benign STT the commonest tumor was lipoma (25\%), followed by haemangioma, neurofibroma and schwanomma (16.7\% each) (Figure 1). Among malignant STT the commonest histopathological diagnosis was Malignant peripheral nerve sheath tumor (31.3\%) followed by Malignant fibrous histiocytoma (12.5\%). There were 3 cases each of synovial sarcoma, liposarcoma, pleomorphic sarcoma and rhabdomyosarcoma (Figure 2).

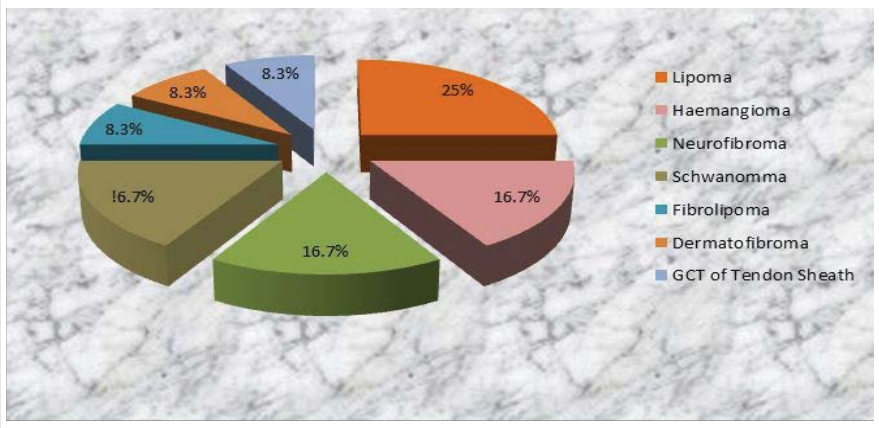

Figure 1: Histopathological diagnosis of benign soft tissue tumors (Pie Diagram).

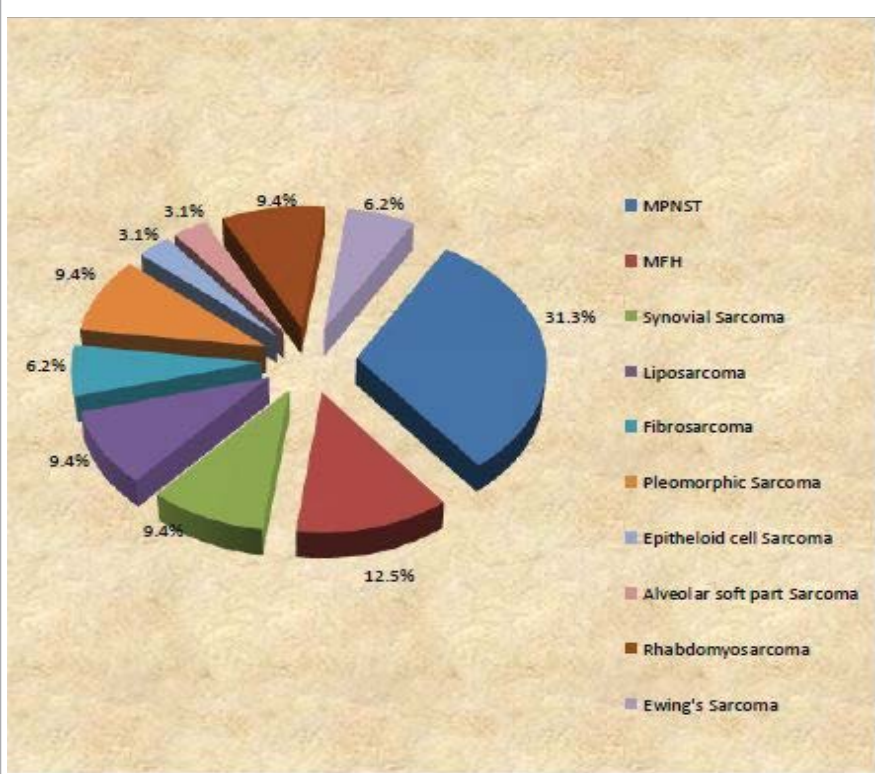

Figure 2: Histopathological diagnosis of malignant soft tissue tumors (Pie Diagram). 
MFH malignant fibrohistocytic tumor: Out of the 32 cases of soft tissue sarcomas, 15 (46.87\%) were Grade 2, 13 (40.63\%) were Grade 3 and $4(12.5 \%)$ were Grade 1 . MPNST had the largest number of cases with Grade 3 (31.3\%) (Table 1). It was observed that maximum number of cases of Grade 1 and Grade 2 were in the age group 31-40 years, while that of Grade 3 were in the age group 71-80 years. The mean age of patients with Grade 1, 2 and 3 STS was 42.5 years, 37.3 years and 50.53 years respectively. The mean size of Grade 1 STS was 8.50 $\mathrm{cm}$ while that of Grade 2 was $8.92 \mathrm{~cm}$. Grade 3 STS had a mean size of $12.51 \mathrm{~cm}$. Maximum number of STS $(\mathrm{n}=15)$ were in the $6-10 \mathrm{~cm}$ size range, of which 8 were Grade 2. However maximum number of Grade $3(\mathrm{n}=7)$ STS had a size of $11-15 \mathrm{~cm}$. The tumor size showed a significant correlation with tumor grade. All the benign STT had low Ki-67 index, while the Ki-67 index was low in 12 STS and high in 20 STS (Figure 3).

Maximum number of STT with low Ki-67 index $(n=7)$ were in the 6-10 cm size range. However maximum number of STT with high Ki67 index $(n=9)$ had a size of $11-15 \mathrm{~cm}$. The size of the tumors showed a significant correlation with Ki-67 index (Table 2).

All the Grade 1 tumors had low Ki-67 index, while all Grade 3 tumors had high Ki-67 index. Grade 2 tumors had variable Ki-67 expression being low in 8 and high in 7 . The relationship between tumor grade and Ki-67 index came out to be statistically significant (Table 3) $\left(\chi^{2}=66.098, \mathrm{df}=6, \mathrm{p}<0.05\right)$.

The histologic type MPNST had the maximum number of tumors with FNCLCC Grade 3. None of the MPNST were Grade 1. All the Grade 3 MPNST had a high Ki-67 index while the Ki-67 index was low in 2 and high in 1 case of Grade 2 MPNST. Tumors of all the three grades were present in the subtype MFH (Figure 4A and 4B) with variable Ki-67 expression in Grade 2 tumors. All the Synovial Sarcoma belonged to FNCLCC Grade 2, with a low Ki-67 index in 1 and high Ki67 index in 2 tumors. None of the Liposarcoma, Fibrosarcoma, (Figure 5A and 5B) Epithelioid Sarcoma and Alveolar soft part sarcoma were Grade 3. The Epithelioid sarcoma and Alveolar soft part sarcoma were only Grade 2 with low Ki-67 index. All the Pleomorphic sarcoma were Grade 3 with low Ki-67 index in 1 and high Ki-67 index in 2 tumors. Ewing's sarcoma had high Ki-67 index in the Grade 2 as well as Grade 3 tumor (Table 4).

\section{Discussion}

The diagnosis and classification of soft tissue tumors is one of the most difficult areas in surgical pathology. World Health Organisation (WHO) has classified soft tissue tumors incorporating detailed clinical, histological and genetic information [2]. Within the various histogenetic categories, soft tissue tumors are usually divided into benign and malignant forms [2].

Once the diagnosis of sarcoma has been established, the foremost consideration is definitive typing and assigning the histological grade which is the single most important factor for predicting the survival rates and metastasis [6].

In our study the mean age of the patients with benign STT was $37.42 \pm 22.45$ years and for STS was $43.31 \pm 22.28$ years. Out of total 12 benign cases, 8 were males and 4 were females with a sex ratio of 2:1.

The difference in the age and sex distribution of our study and others could be because other studies were conducted outside India, except the study by Beg et al., which showed similar results for age and sex distribution [3].

The common sites of STS included the extremities, trunk wall and retroperitoneum. The present study included the cases from these locations as well as from head and neck regions. There were 24 tumors in the lower extremity followed by 10 in the upper extremity. Rest of the tumors were distributed on the back $(n=3)$, head and neck $(n=6)$ and retroperitoneum $(n=1)$. The commonest site of involvement in our study was thigh $(n=8)$, followed by leg $(n=7)$, arm $(n=5)$ and hip $(n=4)$. Similarly in the study conducted by Beg et al., sarcomas were more common in the lower extremity $(n=9)$ followed by abdomen and perineum $(\mathrm{n}=7)$ [3] (Table 5).

In our study the size of the tumors ranged from 1-29 $\mathrm{cm}$. Maximum number of tumors $(\mathrm{n}=18)$ were of the size range $6-10 \mathrm{~cm}$, followed by 13 tumors in the range of $11-15 \mathrm{~cm}$. Only 1 tumor was more than $20 \mathrm{~cm}$.

In the study by Beg et al., size of benign and malignant soft tissue tumors ranged from $0.3-20 \mathrm{~cm}$ and $2-15 \mathrm{~cm}$ respectively [3].

In the present study the commonest benign tumor was lipoma, followed by haemangioma, neurofibroma and schwanomma. Beg et al., also reported lipoma $(n=47)$ to be the commonest benign tumor [3]. In the study by Rudolph et al., commonest benign tumors was, desmoid tumor $(n=16)$ followed by lipoma $(n=8)$ and neurofibroma $(n=8)$ [7].

\begin{tabular}{|c|c|c|c|c|}
\hline Diagnosis & Grade 1 & Grade 2 & Grade 3 & Total \\
\hline Mpnst & 0 & 3 & 7 & 10 \\
\hline Mfh & 1 & 2 & 1 & 4 \\
\hline Synovial Sarcoma & 0 & 3 & 0 & 3 \\
\hline Liposarcoma & 1 & 2 & 0 & 3 \\
\hline Fibrosarcoma & 2 & 0 & 0 & 2 \\
\hline Pleomorphic Sarcoma & 0 & 0 & 3 & 3 \\
\hline Epithelioid Sarcoma & 0 & 1 & 0 & 1 \\
\hline Alveolar Soft Part Sarcoma & 0 & 1 & 0 & 1 \\
\hline Rhabdomyosarcoma & 0 & 2 & 1 & 3 \\
\hline Ewing's Sarcoma & 0 & 1 & 1 & 2 \\
\hline Total & 4 & 15 & 13 & 32 \\
\hline
\end{tabular}

Table 1: FNCLCC grading of soft tissue sarcomas.

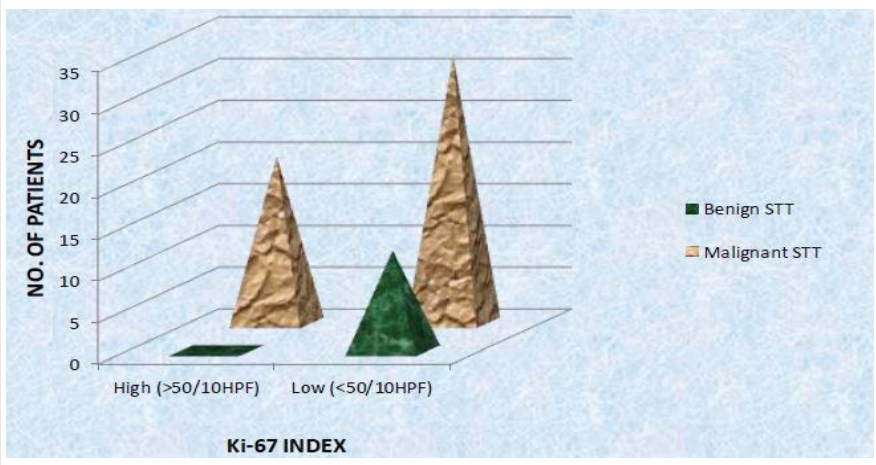

Figure 3: Ki-67 Index of soft tissue tumors (Pyramid Diagram).

\begin{tabular}{|c|c|c|c|}
\hline Size of tumor(Cm) & Low Ki-67 index & High Ki-67 index & Total \\
\hline $1-5$ & 1 & 2 & 3 \\
\hline $6-10$ & 7 & 8 & 15 \\
\hline $11-15$ & 3 & 9 & 12 \\
\hline $16-20$ & 1 & 0 & 1 \\
\hline$>20$ & 0 & 1 & 1 \\
\hline Total & 12 & 20 & 44 \\
\hline & $\mathbf{X}^{2}=\mathbf{2 3 . 8 9}$ & $\mathbf{D f}=\mathbf{8}$ & $\mathbf{P}<\mathbf{0 5}$ \\
\hline
\end{tabular}

Table 2: Ki-67 Index and size of soft tissue tumors. 
Citation: Gupta S, Shakya S, Gill M, Hasija S, Marwah N, et al. (2015) Typing and Grading of Soft Tissue Tumors and their Correlation with Proliferative Marker Ki-67. J Cytol Histol 6: 320. doi:10.4172/2157-7099.1000320

\begin{tabular}{|c|c|c|c|c|}
\hline Ki-67 index & Grade 1 & Grade 2 & Grade 3 & Total \\
\hline High(>50/10hpf) & 0 & 7 & 13 & 20 \\
\hline Low $(<50 / 10 h p f)$ & 4 & 8 & 0 & 12 \\
\hline Total & 4 & 15 & 13 & 32 \\
\hline \multicolumn{2}{|c}{$\mathbf{X}^{2}=\mathbf{6 6 . 0 9 8}$} & $\mathbf{D f = 6}$ & $\mathbf{P}<\mathbf{0 . 0 5}$ \\
\hline
\end{tabular}

Table 3: Correlation between Ki-67 index and FNCLCC grading.

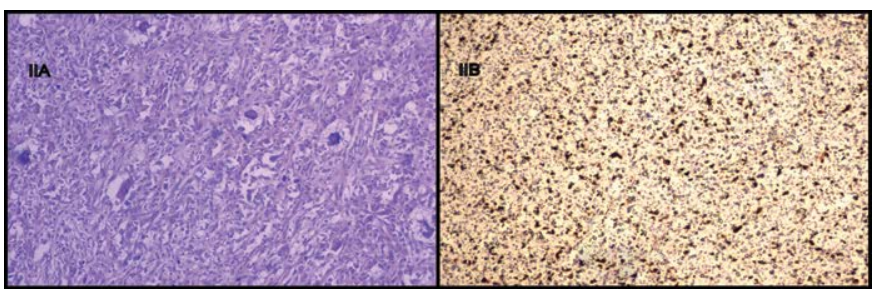

Figure 4: A) H\&E 100X Malignant Fibrous Histiocytoma, B) KI 67 IHC 100X.

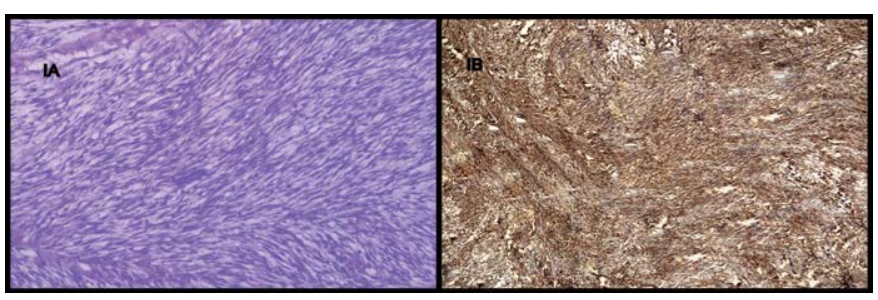

Figure 5: A) H\&E 100X Fibrosarcoma, B) KI 67 IHC.

Histologic grade is a means of quantitating the degree of differentiation by applying a set of histologic criteria. Usually, well-differentiated sarcomas are low grade lesions, whereas poorly differentiated sarcomas are high-grade neoplasms.

At present, it is a generally accepted fact that histologic grade (of which histotype is a key component) is the single best prognostic indicator in soft tissue sarcomas. Multiple studies have confirmed its effectiveness for predicting distant metastases and overall survival. Histologic grade has even shown some value in predicting local recurrence. Grading forms a central and necessary element of the major clinical staging systems for STS and is regarded by most contemporary oncologists as an absolute necessity for clinical decision making.

In our study the commonest histopathological diagnosis was Malignant peripheral nerve sheath tumor $(n=10)$ followed by Malignant fibrous histiocytoma $(n=4)$. There were 3 cases each of Synovial sarcoma, Liposarcoma, Pleomorphic sarcoma and Rhabdomyosarcoma. Two cases each of Fibrosarcoma and Ewing's sarcoma followed by Epithelioid cell sarcoma $(n=1)$ and Alveolar soft part sarcoma $(\mathrm{n}=1)$. These STS were further graded by FNCLCC system into 3 grades, Grade $1(n=4)$, Grade $2(n=15)$ and Grade $3(n=13)$

It was also observed that maximum number of cases of Grade 1 and Grade 2 STS were in the age group 31-40 years, while Grade 3 in the age group 71-80 years. The mean size of Grade 1 tumors was 8.5 $\mathrm{cm}$, that of Grade 2 tumors was $8.9 \mathrm{~cm}$ and that of Grade 3 was 12.5 $\mathrm{cm}$. Rudolph et al., in their study of 132 cases found MFH as the main histopathological diagnosis $(n=45)$, followed by Liposarcoma $(n=35)$ and others $(n=20)$. On FNCLCC grading, the grades that emerged were as follows; Grade $1(n=23)$, Grade $2(n=56)$, Grade $3(n=51)$ [7].

During the last decades there have been considerable changes in the classification of STS. Following an increased use of ancillary techniques, such as electron microscopy, immunostaining, cytogenetics, and molecular genetics, a line of differentiation can be determined in an increasing number of STS [8]. This development has had particular consequence for $\mathrm{MFH}$, which was introduced as a specific entity during the 1960's and quickly became the most common STS subtype $[9,10]$.

This diagnostic term is now reserved (by those who still use it) for the much smaller group of pleomorphic sarcomas which, by current technology, show no definable line of differentiation [11]. As a consequence, the apparent incidence of pleomorphic MFH has fallen sharply over the past 10 years and it is possible that this term may disappear altogether at such time as criteria for the diagnosis of pleomorphic sarcomas showing fibroblastic or myofibroblastic differentiation can be reproducibly defined [12].

In STS a high Ki-67 level has been associated with poor prognosis in several studies. We evaluated the relationship between Ki-67 index

\begin{tabular}{|c|c|c|c|}
\hline Diagnosis & Low Ki-67 index & High Ki-67 index & Total \\
\hline \multicolumn{4}{|c|}{ Mpnst } \\
\hline Grade 1 & 0 & 0 & 0 \\
\hline Grade 2 & 2 & 1 & 3 \\
\hline Grade 3 & 0 & 7 & 7 \\
\hline \multicolumn{4}{|c|}{ Mfh } \\
\hline Grade 1 & 1 & 0 & 1 \\
\hline Grade 2 & 1 & 1 & 2 \\
\hline Grade 3 & 0 & 1 & 1 \\
\hline \multicolumn{4}{|c|}{ Synovial sarcoma } \\
\hline Grade 1 & 0 & 0 & 0 \\
\hline Grade 2 & 1 & 2 & 3 \\
\hline Grade 3 & 0 & 0 & 0 \\
\hline \multicolumn{4}{|c|}{ Liposarcoma } \\
\hline Grade 1 & 1 & 0 & 1 \\
\hline Grade 2 & 1 & 1 & 2 \\
\hline Grade 3 & 0 & 0 & 0 \\
\hline \multicolumn{4}{|c|}{ Fibrosarcoma } \\
\hline Grade 1 & 2 & 0 & 2 \\
\hline Grade 2 & 0 & 0 & 0 \\
\hline Grade 3 & 0 & 0 & 0 \\
\hline \multicolumn{4}{|c|}{ Pleomorphic sarcoma } \\
\hline Grade 1 & 0 & 0 & 0 \\
\hline Grade 2 & 0 & 0 & 0 \\
\hline Grade 3 & 1 & 2 & 3 \\
\hline \multicolumn{4}{|c|}{ Epithelioid sarcoma } \\
\hline Grade 1 & 0 & 0 & 0 \\
\hline Grade 2 & 1 & 0 & 1 \\
\hline Grade 3 & 0 & 0 & 0 \\
\hline \multicolumn{4}{|c|}{ Alveolar soft part sarcoma } \\
\hline Grade 1 & 0 & 0 & 0 \\
\hline Grade 2 & 1 & 0 & 1 \\
\hline Grade 3 & 0 & 0 & 0 \\
\hline \multicolumn{4}{|c|}{ Rhabdomyosarcoma } \\
\hline Grade 1 & 0 & 0 & 0 \\
\hline Grade 2 & 1 & 1 & 2 \\
\hline Grade 3 & 0 & 1 & 1 \\
\hline \multicolumn{4}{|c|}{ Ewing's sarcoma } \\
\hline Grade 1 & 0 & 0 & 0 \\
\hline Grade 2 & 0 & 1 & 1 \\
\hline Grade 3 & 0 & 1 & 1 \\
\hline Total & 13 & 19 & 32 \\
\hline
\end{tabular}

Table 4: Histological type, FNCLCC grade and Ki-67 index. 
Citation: Gupta S, Shakya S, Gill M, Hasija S, Marwah N, et al. (2015) Typing and Grading of Soft Tissue Tumors and their Correlation with Proliferative Marker Ki-67. J Cytol Histol 6: 320. doi:10.4172/2157-7099.1000320

Page 5 of 5

\begin{tabular}{|c|c|c|}
\hline Study group & Number of cases & $\begin{array}{c}\text { \%age of cases in } \\
\text { extremities }\end{array}$ \\
\hline Ueda et al. [13] & 34 & $73.5 \%$ \\
\hline Saddegh et al. [15] & 137 & $61 \%$ \\
\hline Rudolph et al. [7] & 132 & $49.2 \%$ \\
\hline Coindre et al. [6] & 1240 & $59 \%$ \\
\hline Zagars et al. [16] & 1225 & $69.2 \%$ \\
\hline Beg et al. [3] & 21 & $47.6 \%$ \\
\hline Present Study & 44 & $90.6 \%$ \\
\hline
\end{tabular}

Table 5: Comparison of distribution of cases in extremities in various studies.

and histologic grade by chi-square test and Spearman correlation coefficient.

In our study majority of the tumors with low Ki-67 index were in the size range of $6-10 \mathrm{~cm}$. Amongst the tumors with high $\mathrm{Ki}-67 \mathrm{index}$, nine were in the size range of $11-15 \mathrm{~cm}$ while eight had a size range of 6-10 cm. One STT with low Ki-67 index fell in the size range $16-20 \mathrm{~cm}$, while one STT with high $\mathrm{Ki}-67$ index had size $>20 \mathrm{~cm}$. The Ki-67 index correlated significantly with tumor size in the present study. Ueda et al., in their study however found no difference in tumor size between the low and high index groups [13].

In the present study, all the cases of benign STT had low proliferative index. Among the soft tissue sarcomas, all the Grade $1(n=4)$ sarcomas had low Ki-67 index. Of the 15 Grade 2 sarcomas, 8 had low Ki-67 index while 7 had high Ki-67 index. All the 13 Grade 3 sarcomas had high Ki-67 index. The relationship between Ki-67 index and tumor grade came out to be statistically significant $(\mathrm{P}<0.00)$. The Ki-67 index had positive correlation with histological grade. Similar to our study Sahin et al., also reported that the Ki-67 index was low in benign and Grade 1 tumors, while it was high in Grade 2,3 tumors in their study [14].

Grading can be considered as a morphologic translation of molecular events that determine tumor aggressiveness. However, the relative rarity and complex histologic features of STS frequently make defining their precise grade of malignancy difficult even among the experienced pathologists. Therefore further evaluation of the cell proliferation in STS might make assesment of the prognosis more accurate $[15,16]$.

\section{Conclusion}

Soft tissue sarcomas comprise a heterogeneous group of tumors with diverse outcomes determined by numerous factors. Proliferation and cellular differentiation are inversely related processes. There is strong correlation between the proliferation rate of tumors and clinical outcome. Immunohistochemical assessment of cell proliferation is more practical and easier than the other techniques and may yield better information in the current prognostic models for STS. In the present study, we demonstrated a positive correlation between Ki-67 index and histologic grade.

Newer approaches such as assessment of proliferation markers when combined with grading provide additional useful information for risk stratification and management.

\section{References}

1. Weiss SW, Goldblum JR (2008) General considerations. In: Weiss SW Goldblum JR, editors. Enzinger and Weiss's Soft tissue tumors. (5th edn), Mosby: Inc Missouri.

2. Fletcher CDM, Unni KK, Mertens F (2002) World Health Organization classification of tumors. In: Fletcher CDM, Goldblum JR, editors. Pathology and genetics of tumors of soft tissue and bone. (4th edn), Lyon: IARC Press.

3. Beg S, Vasenwala SM, Haider N, Ahmad SS, Maheshwari V, et al. (2012) A comparison of cytological and histopathological findings and role of immunostains in the diagnosis of soft tissue tumors. J Cytol 29: 125-130.

4. Clark MA, Fisher C, Judson I, Thomas JM (2005) Soft-tissue sarcomas in adults. N Engl J Med 353: 701-711.

5. Jensen OM, Høgh J, Ostgaard SE, Nordentoft AM, Sneppen O (1991) Histopathological grading of soft tissue tumours. Prognostic significance in a prospective study of 278 consecutive cases. J Pathol 163: 19-24.

6. Coindre JM (2006) Grading of soft tissue sarcomas: review and update. Arch Pathol Lab Med 130: 1448-1453.

7. Rudolph P, Kellner U, Chassevent A, Collin F, Bonichon F, et al. (1997) Prognostic relevance of a novel proliferation marker, Ki-S1, for soft-tissue sarcoma. A multivariate study. Am J Pathol 150: 1997-2007.

8. Engellau J (2004) Prognostic factors in soft tissue sarcoma. Tissue microarray for immunostaining, the importance of whole-tumor sections and timedependence. Acta Orthop Scand Suppl 75: 2 p preceding table of contents-52, backcover.

9. O’Brien JE, Stout AP (1967) Malignant fibrous xanthomas. Cancer 17: 14451456.

10. OZZELLO L, STOUT AP, MURRAY MR (1963) Cultural characteristics of malignant histiocytomas and fibrous xanthomas. Cancer 16: 331-344.

11. Weiss SW, Goldblum JR (2008) Malignant fibrous histiocytoma. In: Weiss SW, Goldblum JR, editors. Enzinger and Weiss's Soft Tissue Tumors. 5th ed. Mosby: Inc Missouri.

12. Fletcher CDM, Berg Van Den E, Molenaar WM (2002) So-called Fibrohistiocytic Tumors. In: Fletcher CDM, Goldblum JR, editors. Pathology and genetics of tumors of soft tissue and bone. 4th ed. Lyon: IARC.

13. Ueda T, Aozasa K, Tsujimoto M, Ohsawa M, Uchida A, et al. (1989) Prognostic significance of Ki-67 reactivity in soft tissue sarcomas. Cancer 63: 1607-1611.

14. Sahin AA, Ro JY, el-Naggar AK, Wilson PL, Teague K, et al. (1991) Tumor proliferative fraction in solid malignant neoplasms. A comparative study of Ki67 immunostaining and flow cytometric determinations. Am J Clin Pathol 96: 512-519.

15. Saddegh MK, Lindholm J, Lundberg A, Nilsonne U, Kreicbergs A (1992) Staging of soft-tissue sarcomas. Prognostic analysis of clinical and pathological features. J Bone Joint Surg Br 74: 495-500.

16. Zagars GK, Ballo MT, Pisters PW, Pollock RE, Patel SR, et al. (2003) Prognostic factors for patients with localized soft-tissue sarcoma treated with conservation surgery and radiation therapy: an analysis of 1225 patients. Cancer 97: 2530-2543. 